\title{
Available and emerging treatments for Parkinson's disease: a review
}

This article was published in the following Dove Press journal:

Drug Design, Development and Therapy

29 April 2011

Number of times this article has been viewed

\author{
Patrick Hickey \\ Mark Stacy \\ Division of Neurology, Duke \\ University Medical Center, \\ Durham, NC, USA
}

Correspondence: Mark Stacy

Division of Neurology, Duke University

Medical Center, 932 Morreene Road,

Durham, NC, USA

Tel +19196682828

Fax + I 9196814935

Email mark.stacy@duke.edu
Abstract: Parkinson's disease is a commonly encountered neurodegenerative disorder primarily found in aged populations. A number of medications are available to control symptoms, although these are less effective in advanced disease. Deep brain stimulation provides a practicable alternative at this stage, although a minority of patients meet the strict criteria for surgery. Novel medications that provide enhanced symptomatic control remain in developmental demand. Both gene and cell-based therapies have shown promise in early clinical studies. A major unmet need is a treatment that slows or stops disease progression.

Keywords: Parkinson's disease, levodopa, motor fluctuations, adenosine A2A antagonists, deep brain stimulation, gene therapy

\section{Introduction}

Parkinson's disease (PD) is a common neurodegenerative disorder, manifested clinically by bradykinesia, resting tremor, rigidity, and postural instability. ${ }^{1}$ The cause of PD is unknown. Although there are a number of medications available for those affected, treatment remains focused on these motor, as well as nonmotor, symptoms. A number of environmental factors have been implicated in PD. ${ }^{2}$ However, aging is the most significant risk factor for development of the disease. With the number of people in the United States aged above 65 years expected to double by $2030,{ }^{3}$ a major unmet need is new and novel treatments that address both the symptoms of PD and its progressive nature.

Since its introduction in $1968,{ }^{4}$ levodopa has remained the most efficacious treatment of PD. Unfortunately, its use is associated with motor complications such as wearing off, dyskinesias, and 'on-off' phenomenon. ${ }^{1,5-7}$ These complications occur in about $50 \%$ of levodopa-treated patients who have received the drug for more than 5 years, in $80 \%$ of patients treated for 10 years, and in nearly all patients with youngonset disease. ${ }^{8-10}$ Additionally, levodopa targets only dopamine deficiency, although other neuronal targets, such as acetylcholine, glutamate, and $N$-methyl-D-aspartic acid, may be important. ${ }^{10,11}$ Novel therapeutic strategies continue to be in developmental demand. This review will focus on current medical and surgical treatment strategies for PD as well as emerging technologies.

\section{Dopaminergic stimulation}

The degeneration of the dopaminergic system associated with PD alters the normal physiology of the basal ganglia. There is substantial scientific evidence to support that under normal circumstances, dopaminergic neurons in the substantia nigra pars 
compacta $(\mathrm{SNc})$ fire at a nearly constant rate, independent of body movement. This steady firing maintains striatal dopamine at a fairly constant level, providing continuous stimulation of striatal dopamine receptors. ${ }^{12-16}$ However, with the progressive loss of dopamine secreting neurons in the SNc in PD, striatal dopamine levels become increasingly dependent on the availability of peripherally administered levodopa. ${ }^{17}$ Immediate-release preparations of levodopa have a half-life of $1-3 h,{ }^{18}$ the length of which can be modestly increased by inhibition of peripheral catechol- $O$-methyltransferase (COMT) using either entacapone or tolcapone. ${ }^{19,20}$ This nonphysiologic stimulation further disrupts an already unstable striatum and is believed to be the basis for the motor fluctuations seen with chronic levodopa therapy. ${ }^{21,22}$ In fact, continuous infusion of levodopa has been shown to reduce 'off' time and dyskinesias in patients with PD and motor fluctuations, ${ }^{23-25}$ and longer-acting dopaminergic drugs, such as dopamine agonists, are associated with dyskinesias to a lesser extent. ${ }^{26,27}$ These findings have led to the evaluation of long-acting levodopa strategies to treat the motor symptoms of PD. ${ }^{28}$

\section{Continuous dopaminergic stimulation with frequent levodopa dosing}

The Stalevo Reduction in Dyskinesia Evaluation in Parkinson's Disease (STRIDE-PD) study was a double-blind trial comparing the risk of developing dyskinesias in PD patients initiated on the combination of levodopa/carbidopa/ entacapone (LCE) versus levodopa/carbidopa (LC) administered 4 times daily. In the trial, subjects treated with LCE demonstrated a shorter time to dyskinesia onset and increased frequency of dyskinesias compared to those treated with standard LC. ${ }^{29}$ This occurred despite extended elimination half-life and plasma area under the curve of levodopa associated with LCE. ${ }^{20}$ Given the compromise of 4 times daily dosing, the authors speculated that the goal of continuous dopaminergic stimulation may not have been achieved with the chosen dosing frequency. ${ }^{30}$

An unanticipated outcome of the study was a higher incidence of prostate cancer in those treated with LCE. Although it has been postulated that COMT may play a protective role, the relationship of COMT inhibition or entacapone and prostate cancer is not defined. ${ }^{31,32}$ The Food and Drug Administration (FDA) has announced a safety review regarding this imbalance and the possible impact it may have on those patients treated with LCE.

\section{Duodenal levodopa}

Studies of intravenous and enteral levodopa have shown a more predictable motor control and reduced fluctuations when compared to oral therapy. ${ }^{33,34}$ These observations led to the development of a concentrated levodopa/carbidopa formulation intended for long-term enteral infusion therapy. ${ }^{35}$ By providing more consistent plasma levodopa levels, this gel formulation (Duodopa ${ }^{\circledR}$; Solvay Pharmaceuticals, Bruxelles, Belgium) is delivered via a transabdominal port placed directly into the duodenum and has proven to be a successful therapeutic option. ${ }^{36}$ Clinical trials have proven the safety and efficacy of this delivery method with improvements in both motor scores and quality of life measures. ${ }^{37}$ In one 12-month study, the average daily 'off' time was reduced from 284 to $30 \mathrm{~min} / \mathrm{day}$, and troublesome dyskinesias were reduced from 156 to $40 \mathrm{~min} /$ day. ${ }^{25}$ This therapy is now considered a viable treatment alternative for advanced patients. ${ }^{38}$ Although generally reserved as a last-line therapy after subcutaneous treatments or deep brain stimulation (DBS) has failed or been deemed not feasible, the safety and tolerability of this therapy may warrant use earlier in the course of PD. ${ }^{39}$

Duodopa received approval by the FDA in 2000 as an orphan drug and continues to be evaluated for its clinical use. There are currently nine studies under way to further clarify the efficacy of enteral levodopa. The DuoCOMT study is designed to determine the effects of oral COMT inhibitors, in the form of tolcapone and entacapone, on plasma concentrations of parenterally delivered levodopa. ${ }^{40}$ The medication's effect on the sympathetic nervous system, ${ }^{41}$ its cost-benefit versus standard PD treatments, ${ }^{42}$ as well as its pharmacodynamics continue to be evaluated in controlled studies. ${ }^{43}$ Although there have certainly been difficulties associated with the delivery system such as tube dislocations and clogging, demand for alternative treatments continues to drive improvements in parenteral levodopa delivery. ${ }^{38}$

\section{Levodopa formulations}

After oral ingestion, levodopa is actively transported in the duodenum by a specific, large neutral L-amino acid carrier. ${ }^{18}$ To reach this site, it must pass through the stomach where it is subject to erratic gastric emptying in a high percentage of patients with PD. ${ }^{44,45}$ Because there is no gastric absorption, irregular gastric emptying is a major obstacle in the plasma concentration of levodopa and may contribute to motor fluctuations in advanced disease. ${ }^{46}$

Liquids pass through the stomach more quickly than solids and reach the small intestine faster, perhaps ensuring 
more rapid and efficient absorption. ${ }^{47}$ Melevodopa is an effervescent prodrug with about 250 times higher water solubility compared to tablet levodopa, which allows faster and more consistent absorption and a more rapid onset of action (Table 1). ${ }^{48,49}$ This quicker and a more predictable time to effect allows improved mobility for patients which can translate into less daily 'off' time, a useful measure of drug efficacy in PD patients. ${ }^{49}$ Effervescent formulations continue to demonstrate safety and tolerability in clinical trials and warrant further exploration. ${ }^{50}$

Two other levodopa formulations are currently in development in an attempt to improve absorption. XP21279 is a levodopa prodrug that is designed for absorption by transporter mechanisms expressed throughout the entire gastrointestinal tract, not just the duodenum, and is currently in Phase I trials. ${ }^{51,52}$ IPX066 is an extended-release carbidopa-levodopa formulation fashioned to produce quick and sustained concentrations of levodopa with the goal of improved and more reliable control of PD symptoms. It proved its superiority to immediate-release levodopa in a study of 27 PD patients with at least 3 hours of daily 'off' time. ${ }^{53}$ IPX066 decreased 'off' time by 2 hours and increased 'on' time by nearly 2 hours without a significant increase in troublesome dyskinesias. APEX-PD is a Phase III randomized, double blind, placebo-controlled study under way to evaluate the safety and efficacy of IPX066 over 30 weeks. ${ }^{54}$ The sustained action may help to reduce dosing frequency and improve compliance as well.

\section{Adenosine $\mathrm{A} 2 \mathrm{~A}$ antagonists}

Several nondopaminergic therapies have been explored in the treatment of $\mathrm{PD}$ and the adenosine $\mathrm{A} 2 \mathrm{~A}$ receptors antagonists seem promising. Of the four subtypes of adenosine receptors, the A2A subtype is densely localized in the basal ganglia. Here, they are concentrated on $\gamma$-aminobutyric acid (GABA)containing medium spiny neurons of the indirect pathway that project from the striatum to the globus pallidus externa. ${ }^{55,56}$ Antagonism of adenosine A2A receptors facilitates intrastriatal GABA release, reducing striatopallidal neuronal overactivity. This reduction helps to increase indirect inhibitory output from the striatum to the globus pallidus, thus restoring balance between the basal ganglia output pathways. ${ }^{57,58}$

Based on encouraging results in both rat and primate PD models, ${ }^{59-63}$ the adenosine A2A receptor antagonist istradefylline has been explored in a number of human clinical trials. A small Phase I study showed potentiation of the antiparkinsonian effects of concomitant low-dose levodopa, a measurable prolongation of 'on' time, and no exacerbation of dyskinesias. ${ }^{64}$ A subsequent 12 -week, randomized, placebo-controlled, double-blind trial in levodopa-treated patients with advanced PD demonstrated a significant reduction in 'off' time, although there was a measurable increase in 'on' time with dyskinesias. ${ }^{65}$ Two large, randomized, double-blind, placebo-controlled, Phase II studies also demonstrated significant reductions in 'off' time over 12 weeks in advanced PD patients, many of whom were also taking multiple adjunctive therapies in addition to levodopa. ${ }^{66,67}$ These results were confirmed by a large Phase III clinical trial where istradefyllinetreated patients had a 0.7 -hour reduction in daily 'off' time compared to placebo, which was sustained over 12 weeks. ${ }^{68}$ This reduction in 'off' time translated into increased functional 'on' time in this advanced PD group, the vast majority of whom were already taking adjunctive therapies. However, these results were not replicated in another trial. ${ }^{69}$ The effect of istradefylline on levodopainduced dyskinesias in patients with advanced PD is also being investigated. ${ }^{70}$

A number of other adenosine $\mathrm{A} 2 \mathrm{~A}$ antagonists are currently under development as well, some of which have early clinical data. Initial reports concerning vipadenant (BIIB014/V2006) were promising, but this compound will not be developed, secondary to interest in favor of 'next generation' A2A antagonists held by that sponsor. These are expected to enter early Phase I studies in 2011. ${ }^{71}$ Preladenant has reached a Phase II, randomized, placebo-controlled trial in moderate to severe PD patients with motor fluctuations and dyskinesias. In this setting, it showed significant reductions in 'off' time and increased 'on' time without exacerbation of dyskinesias. ${ }^{72-74}$ Further studies of preladenant are ongoing in both early and advanced PD patients. ${ }^{75,76}$ ST-1535 is another potential candidate currently in Phase I development by Sigma-tau (Gaithersburg, MD). ${ }^{77}$ SYN-115, in development by Synosia (Basel, Switzerland), will soon enter Phase IIb trials after encouraging functional magnetic resonance imaging (fMRI) and early clinical data. ${ }^{78}$

Perhaps more exciting than symptomatic improvement with adenosine A2A antagonists is data suggesting a neuroprotective one. Higher intake of caffeine, a nonselective adenosine antagonist, has been shown in a number of studies to have a protective effect on development of PD in diverse populations. ${ }^{79-82}$ These encouraging findings have translated into similar results in both mice and primate models of PD, 
which have demonstrated a reduction in neuronal loss with concomitant use of A2A antagonists. ${ }^{83-85}$ The mechanism of this apparent protection is not well understood, although it may be a result of altered release of glutamate and aspartate in the brain. ${ }^{86}$

\section{Monoamine oxidase $B$ inhibitors}

Inhibitors of monoamine oxidase type B (MAO-b) are receiving renewed attention based on two recent trials investigating a possible disease-modifying effect of rasagiline, an MAO-b inhibitor shown to have neuroprotective effects in animal models of PD. ${ }^{87,88}$ In an attempt to overcome the barriers to the study drug washout, the previous method to separate disease modifying from symptomatic treatment effect, a delayed-start design was employed. In this paradigm, the early start group received the active study drug for the full period of the study and the delayed start group received a placebo through the first phase of the study. After a predetermined period of time, the placebo group switched to active therapy, and both groups received the active drug for the second phase. Any difference measured between the two groups at the end may be interpreted as a disease-modifying effect of the medication.

An initial, 12-month study of rasagiline using this unique design demonstrated less progression in terms of total Unified Parkinson's Disease Rating Scale (UPDRS) scores for those randomized to immediate treatment compared to those delayed by 6 months. ${ }^{89}$ The authors concluded that one explanation for these findings is a disease-modifying effect of the medication, a slowing of motor disability progression. Based on these results, the Attenuation of Disease Progression with Rasagiline Once-daily (ADAGIO) study was developed. This larger, double-blind, placebo-controlled, delayed-start trial was designed to further evaluate whether rasagiline was able to affect the rate of progression of $\mathrm{PD}$ in patients over 72 weeks. ${ }^{90}$ Subjects randomized to early lower dose (1 mg/ day) treatment met all prespecified endpoints showing a sustained slower rate of progression and significant improvement in the change in total UPDRS score compared to those delayed to treatment. Although those randomized to early higher dose ( $2 \mathrm{mg} /$ day) did show a slower rate of progression compared to those delayed to treatment, the change in total UPDRS did not differ significantly. These confounding results suggested a disease-modifying effect for lower dose rasagiline, although the same conclusion could not be drawn for higher dose. Rasagiline remains a useful treatment in both early and moderate $\mathrm{PD}$, but its neuroprotective properties continue to be the subject of much debate. ${ }^{91,92}$
Safinamide is an aminoamide derivative with multiple mechanisms of action, currently in Phase III clinical trial development. It acts as a highly selective, reversible inhibitor of MAO-b, reduces the reuptake of dopamine, blocks voltage-dependent sodium/calcium channels, and inhibits glutamate release. ${ }^{93,94}$ This combination of actions suggests some potential for neuroprotection and symptomatic relief in PD. An early study showed that safinamide was associated with improved motor UPDRS scores in early PD patients especially when added to those on dopamine agonist monotherapy. ${ }^{95}$ It is now being investigated as an adjunct therapy for patients stabilized on levodopa. Early results from a 6-month, Phase III, double-blind, placebocontrolled trial indicate significant improvement in 'on' time, 1.3 hours/day in the treatment group compared to 0.7 hours/ day in the placebo group. ${ }^{96}$ This improvement came without an increase in troublesome dyskinesias. Significant improvements in daily 'off' time, 'off' time after the first morning levodopa dose, UPDRS III during 'on' phase, and clinical global improvement change and severity scores were also reported. Further trials are ongoing to investigate the effect of safinamide on levodopa-induced dyskinesias and motor fluctuations. ${ }^{97,98}$

\section{Dopamine agonists}

Dopamine agonists provide an important option in the treatments available for PD, and there is long-term data to support their efficacy and safety. Compared to levodopa, dopamine agonists provide modest symptomatic benefit and are associated with higher incidence of side effects such as hallucinations, edema, sudden sleep attacks, and impulse control disorders (ICD). ${ }^{99}$ However, motor fluctuations such as dyskinesias are less common with these medications. ${ }^{99-101}$

In the Comparison of the Agonist Pramipexole versus Levodopa on Motor Complications of Parkinson's Disease (CALM-PD) study, patients were randomized to initial treatment with either levodopa or pramipexole and followed for up to 4 years. A subset of patients were evaluated with regular $\left[{ }^{123} \mathrm{I}\right] \beta$-CIT SPECT imaging to follow the rate of dopamine transporter (DAT) loss as a measure of dopaminergic neuronal concentration in the striatum. There was a significant reduction in transporter loss at each time point over the 46 months in the pramipexole group. ${ }^{102}$ Similar results were seen in the Ropinirole as Early Therapy versus L-dopa Positron Emission Tomography (REAL-PET) study, which used ${ }^{18} \mathrm{~F}$-dopa positron emission tomography as a biomarker of neuronal degeneration in a similar study design. 
Again, there was a significant reduction in tracer uptake decline in the ropinirole group compared with the levodopa group over 2 years. ${ }^{103}$ These findings offered evidence of a possible disease-modifying effect of dopamine agonists, something that had been demonstrated in vitro previously.

The PRamipexole On Underlying Disease (PROUD) study utilized a delayed start design to examine whether immediate treatment with pramipexole $1.5 \mathrm{mg}$ /day had any evidence of disease modification compared to delayed treatment. After 15 months, there was no significant difference between the two groups in terms of change in total UPDRS score from baseline, suggesting no modification of disease over this period. ${ }^{104} \mathrm{~A}$ subset of 150 patients underwent striatal DAT density evaluation by $\left[{ }^{123} \mathrm{I}\right] \mathrm{FP}-\mathrm{CIT}$ SPECT to compare decline in neuronal density, and these results may shed further light on any lasting benefit in disease progression. ${ }^{105}$

Both ropinirole and pramipexole have recently been approved as once daily prolonged-release formulations, providing important additions to the treatment options in both early and advanced PD. In comparator studies between immediate- and prolonged-release formulations, both medications showed similar efficacy in treating motor symptoms. The Efficacy and Safety Evaluation in PD-Monotherapy (EASE-PD Monotherapy) study was a multicenter, randomized, double-blinded, crossover study involving 161 PD patients that proved noninferiority between ropinirole immediate release and ropinirole prolonged release. ${ }^{106}$ It also showed that an overnight switch from immediate to prolonged release with an approximate 1:1 conversion was well tolerated. Of great importance, especially when considering treatment options, was the finding that overall compliance was significantly better in the once-a-day prolonged-release group compared to the three-times-a-day immediate-release group. The Efficacy and Safety Evaluation in PD-Adjunct (EASE-PD Adjunct) study randomized 393 advanced PD patients who were suboptimally controlled on levodopa to either prolonged release ropinirole or placebo in a $1: 1$ fashion. ${ }^{107}$ The authors found significant improvement in daily 'off' time, evident as early as 2 weeks after treatment initiation, ${ }^{108}$ UPDRS motor scores, and the ability to substantially lower daily levodopa dose.

Extended-release pramipexole also showed similar efficacy to immediate-release formulation in an 18-week, randomized, double-blind, placebo and active comparatorcontrolled trial. ${ }^{109} \mathrm{~A}$ total of 259 patients were randomized to either extended-release pramipexole, immediate-release pramipexole, or placebo in a 2:2:1 ratio with rescue levodopa allowed if deemed necessary. Both pramipexole groups showed significant improvement in PD symptoms to a similar degree compared to placebo. Again, the potential for increased compliance with once daily dosing is an attractive option with the extended-release formulation.

One frequent limiting factor in the use of dopamine agonist is the development of ICD. Increased incidence of pathologic gambling, compulsive sexual behavior, compulsive buying, and binge or compulsive eating have garnered increased attention in PD and can have a devastating impact on the lives of those affected. ${ }^{110-113}$ ICD are under-reported in clinical practice, although up to $17 \%$ of PD patients taking a dopamine agonist may be affected. ${ }^{113}$ The DOMINION study, a cross-sectional study of over 3000 PD patients treated with at least one PD medication for at least 1 year with a demonstrable response, showed a 2- to 3.5-fold increased risk of ICD associated with dopamine agonist treatment. ${ }^{114}$ However, levodopa-treated patients also experienced ICD, especially with higher doses. In this population, all ICDs were seen with similar frequency, and more than a quarter of patients had more than one concurrent ICD. This further highlights the need for proper patient education and screening during treatment with these medications, as many patients will not volunteer such difficulties. ${ }^{113}$

Amantadine showed marked benefit in a small study of 17 PD patients with severe pathologic gambling that did not improve with medication reduction or behavioral strategies. ${ }^{115}$ The authors hypothesized that the antiglutamatergic actions of amantadine may underlie its effectiveness. However, in the DOMINION patient population, amantadine use was associated with a higher incidence of at least one active ICD when compared to no amantadine use. ${ }^{116}$ This remained true after controlling for dopamine agonist use as well as levodopa dosage and highlights the need for further research to elucidate its relationship with ICD. A study evaluating whether naltrexone, an opioid antagonist, improves ICD symptoms is under way. ${ }^{117}$

\section{Nanotechnology}

One of the most formidable limitations to drug efficacy in PD is restricted entry to the central nervous system (CNS) by the blood-brain barrier (BBB). The BBB allows the free passage of small lipophilic molecules; however, large, hydrophobic, or charged molecules require facilitated transport. Dopamine, a polar compound, is restricted from free entry into the CNS. Nanotechnology can overcome this impediment by packaging drugs into small (10-1000 nm) nanoparticles, which more readily cross the BBB. ${ }^{118}$ In addition, these structures can 
avoid traditional degradation lines and better target specific CNS structures, helping to reduce systemic side effects. ${ }^{119}$ Ideally, nanoparticles would be part of a system able to automate drug delivery, sensing when medication is needed and delivering it to a specific target. ${ }^{120}$

Perhaps more intriguing, nanotechnology has potential applications in treatments that reduce and reverse neuropathology as well as promote the regeneration of damaged neurons. With the ability to target signaling pathways, gene products, and protein aberrations involved in neurodegeneration, nanotherapies may provide unique neuroprotective strategies. ${ }^{121}$

\section{DBS}

Since it was first discovered that high-frequency stimulation of deep brain structures was able to replicate the therapeutic effect of lesioning procedures, surgical techniques to treat PD have continued to evolve. ${ }^{122-125} \mathrm{DBS}$ is now the preferred surgical procedure to treat advanced PD and is more effective at treating motor disability and improving quality of life in PD patients with motor fluctuations than best medial therapy. ${ }^{126,127}$ Using microelectrode recording, electrophysiological exploration of the target structures is undertaken under local or general anesthesia. Local anesthesia allows the advantage of intraoperative testing of the effects of DBS and perhaps more precise localization. ${ }^{127}$ Once the optimal target is found, the electrode is replaced by a chronic lead, which will then be fixed to a pulse generator implanted under the skin, typically in the subclavicular area.

The most common target for DBS in PD is the subthalamic nucleus (STN). However, the globus pallidus interna (GPi) has often been considered a target for patients with severe dyskinesias. A recently published randomized trial comparing the two targets in 299 patients with idiopathic PD showed no significant difference in terms of change in motor function from baseline to 24 months. ${ }^{128}$ Function was blindly assessed using the UPDRS III, with a reduction of 10.7 points in the subthalmic-stimulation group and a reduction of 11.8 points in the GPi group. However, a number of nonmotor elements did show a notable difference. Those in the subthalamic group showed a significant worsening in depression and visuomotor speed, while those in the pallidal group required more dopaminergic medication. Both groups rated comparably in quality of life measures. The authors concluded that both are feasible targets and that nonmotor measures are important determinants in target selection.

As PD advances, falls and gait freezing become a major source of disability for patients. These symptoms are not well managed with current pharmacotherapy options or DBS targets. Stimulation of the pedunculopontine nucleus (PPN) has been explored as a target to improve postural instability in advanced PD. Early open-label studies demonstrated the safety of the procedure and detailed encouraging results in terms of motor function. ${ }^{129,130}$ However, the outcomes of recent blinded studies have been mixed. In six patients with advanced PD, unilateral PPN stimulation showed no objective motor benefit, although improvement in patient reported falls after 1 year. ${ }^{131}$ Similarly, freezing of gait showed a modest improvement in another small study while other motor symptoms were unchanged. ${ }^{132}$

The exact mechanisms of action of high-frequency stimulation are not known. Electrically jamming the area with high-frequency stimulation may interrupt an irregular feedback loop or abnormal oscillatory activity in a similar manner to lesioning. ${ }^{133,134}$ Alternatively, direct recording during stimulation has shown a change in the neuronal

Table I Medications currently in development for the treatment of Parkinson's disease

\begin{tabular}{|c|c|c|c|}
\hline Drug & Classification & Mechanism & Clinical benefit \\
\hline Melevodopa & Effervescent levodopa prodrug & Converted to dopamine & Improves motor symptoms \\
\hline$X P 21279$ & Levodopa prodrug & Converted to dopamine & Improves motor symptoms \\
\hline IPX066 & Long-acting levodopa & Converted to dopamine & Improves motor symptoms \\
\hline \multirow[t]{2}{*}{ Istradefylline } & Adenosine $\mathrm{A} 2 \mathrm{~A}$ antagonist & Reduces striatal-pallidal firing & Improves motor symptoms \\
\hline & & & Potential for neuroprotection \\
\hline \multirow[t]{2}{*}{ Preladenant } & Adenosine $\mathrm{A} 2 \mathrm{~A}$ antagonist & Reduces striatal-pallidal firing & Improves motor symptoms \\
\hline & & & Potential for neuroprotection \\
\hline \multirow[t]{2}{*}{ ST-I535 } & Adenosine $\mathrm{A} 2 \mathrm{~A}$ antagonist & Reduces striatal-pallidal firing & Improves motor symptoms \\
\hline & & & Potential for neuroprotection \\
\hline \multirow[t]{2}{*}{ SYN-II5 } & Adenosine $\mathrm{A} 2 \mathrm{~A}$ antagonist & Reduces striatal-pallidal firing & Improves motor symptoms \\
\hline & & & Potential for neuroprotection \\
\hline \multirow[t]{3}{*}{ Safinamide } & MAO-b inhibitor & Multiple & Improves motor symptoms \\
\hline & Reduces reuptake of dopamine & & Potential for neuroprotection \\
\hline & Inhibits glutamate release & & \\
\hline
\end{tabular}

Abbreviation: MAO-b, monoamine oxidase type B. 
frequency and firing pattern in the area being stimulated. ${ }^{135}$ Even the downregulation of certain local neurotransmitters and/or hormones may play a strong role as shown by the effect of high-frequency stimulation on cultured cells. ${ }^{136}$

There is emerging interest around a possible neuroprotective effect of DBS. A number of preclinical studies have shown evidence of protection against nigral dopaminergic neuronal degeneration in experimental models of PD in both rats and primates. ${ }^{137-142}$ These authors suggest that the increased activity in the STN may generate glutamate excitotoxicity, which in turn could lead to the degeneration of dopaminergic neurons in the SNc causing disease progression. ${ }^{143-145}$ Therefore, altering the activity of the STN may remove or inhibit a source of glutamatergic input to the SNc leading to protection of dopaminergic cells. ${ }^{138,142}$ An alternative explanation may be that an increase in brain-derived neurotrophic factor associated with DBS is responsible for the neuroprotective effects. ${ }^{142}$

Patients eligible for DBS are those with clinically diagnosed idiopathic PD who are experiencing disabling motor fluctuations despite optimal drug titration, in absence of severe dementia (Mini-Mental State Examination score $>24$ ), and remain responsive to levodopa therapy. ${ }^{127,146-148}$ Currently, the mean disease duration is 14 years before STN-DBS is performed, and less than 5\% of PD patients meet eligibility criteria. ${ }^{149,150}$ If, in fact, DBS offers neuroprotection to dopaminergic cells in the $\mathrm{SNc}$, there will be a substantial degree of disease progression and cell loss in the typical DBS patient prior to intervention. Interest has, therefore, developed regarding early DBS with encouraging results in regards to quality-adjusted life expectancy. ${ }^{151}$ Two studies are currently evaluating the potential for early DBS. The first defines early PD as aged younger than 60 years and is evaluating the difference in Parkinson's Disease Questionnaire-39 (PDQ-39) scores at 24 months in mild to moderate PD patients with motor fluctuations and disease duration for greater than 4 years. ${ }^{152}$ The second is a prospective, randomized trial comparing the time to reach a $20 \%$ worsening in UPDRS motor score and a reduction in medication 24 months after STNDBS in patients $50-75$ years old on dopaminergic therapy for 6 months to 4 years. ${ }^{153}$

\section{Gene therapy}

The theory that a denervated CNS can be functionally repaired by packaging the deficient enzymatic machinery and delivering it back where it has been lost is an attractive option, especially when exploring treatment options for neurodegenerative diseases such as PD. This elegant concept was first envisioned for the treatment of single-gene heritable diseases such as Lesch-Nyhan syndrome in the mid1900s. ${ }^{154,155}$ Since that time, this concept has expanded to include more complex disease states, allowing gene therapy to enter the conversation as a viable goal in treatment of PD. This technique is currently being tested in a number of Phase I and II clinical trials using viral vectors as a means to transport enzymes to the striatum of PD patients, in hopes of providing both symptomatic benefit and possibly neuroprotection in this progressive disease.

In $\mathrm{PD}$, the selective degeneration of dopaminergic neurons from the $\mathrm{SNc}$ is coupled with the loss of dopamine synthesizing enzymes and the brain's ability to produce this essential catecholamine. ${ }^{156}$ The goal of gene therapy is to restore the ability of the brain to once again deliver dopamine to the arid striatum. Packaging novel genes into viral vectors and delivering them to the brain with the goal of enhancing in vivo dopamine production is now under active therapeutic evaluation. Adeno-associated virus (AAV) has been the most commonly utilized vector for such purposes thus far due to its ease of use and safety profile. ${ }^{157,158}$ The potential benefits are compelling: the ability for selective basal ganglia stimulation by bypassing the need for systemic medications, the avoidance of undesirable side effects induced by indiscriminate dopamine activation, and even the possibility for individualized treatment regimens.

Shen et al have used AAV vectors expressing tyrosine hydroxylase (TH), L-amino acid decarboxylase (AADC), and GTP cyclohydrolase 1 (GCH1) and shown sustained behavioral improvement in 6-hydroxydopamine (6-OHDA)lesioned rats. ${ }^{158}$ Muramatsu et al stereotactically injected four 1-methyl-4-phenyl-1,2,3,6-tetrahydropyridine (MPTP)treated monkeys in the unilateral putamen with these vectors. Using the primate parkinsonian rating scale (PPRS), the animals showed marked behavioral improvement that was sustained for up to 10 months. In addition, they were able to demonstrate greater than $90 \%$ transduction of the injected putamen based on immunostaining. ${ }^{159}$

More recently, efforts have been made to deliver all three functional genes in a single viral vector with the goal of more efficient delivery and translational efficacy. ProSavin (owned by Oxford Biomedica, Oxford, UK) developed a lentiviral-based vector. A study in MPTP-treated primates showed significant motor benefit starting 2 weeks after transfection with sustained benefit up to 44 months. Positive effects toward dyskinesias as well as off-time dystonia were also demonstrated. ${ }^{160}$ With these encouraging results, six Parkinson's patients have been injected in a 
Phase I/II study. Two of three in the initial low-dose group have shown a $30 \%$ improvement in the UPDRS III 'off' score at 2 years. ${ }^{161}$ This initial dose-escalation trial will be followed by a second phase to confirm the efficacy of the optimal dose in a randomized trial. ${ }^{162}$

An alternative approach under investigation is the delivery of AADC to the striatum as a means to increase the conversion efficiency of exogenously administered levodopa into active dopamine. This concept was first explored in MPTP-lesioned primates who showed higher conversion rates of L-dopa to dopamine following AADC gene transfer. ${ }^{163}$ Two recent Phase I trials have been completed using this technique, both showed a significant improvement in 'off' time measured by UPDRS at 6 months, with trends in improvement in 'on' time. The majority of patients were able to reduce their total dose of levodopa. Positron emission tomography (PET) with 6- $\left[{ }^{18} \mathrm{~F}\right]$ fluoro-L- $m$-tyrosine (FMT), a tracer for AADC, showed sustained AADC activity in the putamen for as long as 96 weeks. ${ }^{164,165}$

The concept of continuous dopamine delivery has been explored in the setting of levodopa-induced dyskinesias. ${ }^{17,166-168}$ Using gene therapy to attain such a state has been explored in rat models of PD with some success. One such study used recombinant adeno-associated viral (rAAV) to deliver the $\mathrm{TH}$ and $\mathrm{GCH} 1$ genes to the striatum of lesioned rats rendered dyskinetic with daily, pulsatile levodopa injections. The magnitude of dyskinesias was reduced by $85 \%$, and in four of the nine animals, the dyskinesias were completely eliminated. ${ }^{169}$

Taking a different approach to gene transfer, Kaplitt et al used an AAV viral vector to deliver varying concentrations of the glutamic acid decarboxylase (GAD) gene directly into the STN of 12 patients. GAD catalyzes the synthesis of GABA, the major inhibitory neurotransmitter in the brain. The procedure was well tolerated and demonstrated significant improvement in motor UPDRS scores for as long as 12 months along with corresponding changes on FDG-PET. However, given that this was an open-label investigation, further double-blind trials will be needed to explore the benefit of this method. ${ }^{170,171}$

Unfortunately, no available treatment has yet proven to have a definitive neuroprotective effect for patients with PD. ${ }^{172}$ However, the concept of delivering trophic factors to the CNS has evolved considerably to become a major topic in this conversation. Most of the attention has revolved around glial-derived neurotrophic factor (GDNF) since it was first discovered to have a potent protective effect on the survival of midbrain dopaminergic neurons. ${ }^{173}$ Although initial studies with GDNF were disappointing, this was attributed to limited CNS penetration as the trophic factors were delivered via intraventricular cannula. ${ }^{174,175}$ A number of studies have now shown the feasibility of using rAAV to deliver GDNF to the rat striatum and its neuroprotective effect against dopaminergic cell loss following lesioning with 6-OHDA. ${ }^{176,177}$ In addition, GDNF delivery using a lentiviral vector showed prevention of nigrostriatal degeneration and induction of cell regeneration in MPTP-treated primates. ${ }^{178}$ However, GDNF was unable to prevent cell loss in a genetic model of PD using an intranigral injection of mutant human alpha-synuclein via lentiviral vector in rats. ${ }^{179}$

Delivery of GDNF has been studied by way of continuous intraparenchymal infusion into the posterior putamen in human PD patients as well. In one Phase I trial, the procedure was well tolerated and resulted in significant improvement in motor performance in both the 'off-' and 'on-' medication states at 24 months. ${ }^{180,181}$ However, a randomized, doubleblind, placebo-controlled, parallel-group study failed to show a significant improvement in the UPDRS motor 'off' score with bilateral GDNF infusion. ${ }^{182}$

Other trophic factors in the tumor necrosis factor $\alpha$ family are possible targets for neuroprotection in PD as well including neurturin (NTN), the naturally occurring analog of GDNF. NTN has also shown protection of dopaminergic nigral neurons following 6-OHDA lesioning in rats up to 6 months. ${ }^{183,184}$ Additionally, MPTP-treated monkeys demonstrated protection of nigral neurons, preservation of dopaminergic striatal innervation, and prevention of motor dysfunction following injection with an AAV-based vector encoding human NTN. ${ }^{185}$ With these encouraging results, Ceregene Inc (San Diego, CA) completed a Phase I study in which 12 Parkinson's patients received AAV2-NTN (Cere-120) injected into the bilateral putamen in either a low- or high-dose range. The procedure was proven safe, and there was a statistically significant improvement in the UPDRS score in the practically defined 'off' condition, a secondary measure of the study. ${ }^{186}$ A Phase II study is currently under way comparing the change in 'off' time between Cere-120 and placebo in patients with advanced PD. ${ }^{187}$

Nonviral vectors for the safe and effective transfer of genes is a focus of nanotechnology as well, although they may lack the high transfection rate obtained with viral vectors. ${ }^{121}$ Amino-functionalized organically modified silica nanoparticles have been shown to bind and protect plasmid DNA from enzymatic digestion and to provide effective cell transfection in vitro. ${ }^{188}$ These gene-containing nanoparticles may become an effective alternative to restore deficient 
Table 2 Potential gene therapy targets for the treatment of Parkinson's disease

\begin{tabular}{lll}
\hline Genes & Target & Clinical benefit \\
\hline $\begin{array}{l}\text { TH, AADC, GCH } \\
\text { (ProSavin) }\end{array}$ & Putamen & Improves motor symptoms \\
AADC & Striatum & Improves motor symptoms \\
GAD & STN & Improves motor symptoms \\
GDNF & Striatum & Improves motor symptoms \\
& & Potential for neuroprotection \\
Neurturin & Putamen & Improves motor symptoms \\
& & Potential for neuroprotection \\
\hline
\end{tabular}

Abbreviations: TH, tyrosine hydroxylase; AADC, L-amino acid decarboxylase GCH, GTP cyclohydrolase; GAD, glutamic acid decarboxylase; GDNF, glial-derived neurotrophic factor; STN, subthalamic nucleus.

enzymes and deliver neurotrophic factors directly where needed (Table 2).

\section{Conclusion}

$\mathrm{PD}$ is a commonly encountered neurodegenerative disorder of impaired voluntary movements as well as many nonmotor symptoms. Although it has been well recognized within the medical community since its first description by James Parkinson, ${ }^{189}$ the cause of PD remains unknown and the treatment symptomatic. However, since levodopa revolutionized care in the $1960 \mathrm{~s}$, there has continued a torrent of medical and surgical advances that now provide the clinician a number of viable treatment options. The quest for novel treatments, disease-modifying therapeutics, as well as a definitive cure, remains fervent with both basic science and clinical research continuing to add to our understanding of this disabling disorder.

\section{Disclosure}

Dr Stacy has received a grant/research support from Ceregene, IMPAX, Neuraltus Novartis, Schering-Plough, and Parkinson Study Group. He has acted as a consultant for Allergan, Biogen, GE, Novartis, Osmotica, Schering-Plough, and Synosia. He is on the Speakers' Bureau of Allergan, Boeringher-Ingelheim, GlaxoSmithKline, Novartis, and TEVA. He is also on the Safety Monitoring Board for Biogen and Neurologix.

\section{References}

1. Stacy M. Medical treatment of Parkinson disease. Neurol Clin. 2009; 27(3):605-631.

2. Tanner CM, Ross GW, Jewell SA, et al. Occupation and risk of parkinsonism: a multicenter case-control study. Arch Neurol. 2009; 66(9):1106-1113.

3. US Census Bureau. US interim projections by age, sex, race, and hispanic origin: 2000-2050. Available from: http://www.census.gov/population/ www/projections/usinterimproj. Accessed March 18, 2004.
4. Cotzias GC, Papavasiliou PS, Gellene R. Modification of Parkinsonism - chronic treatment with L-dopa. $N$ Engl J Med. 1969;280(7):337-345

5. Lang AE, Lozano AM. Parkinson's disease. First of two parts. $N$ Engl J Med. 1998;339(15):1044-1053.

6. Nutt JG. Motor fluctuations and dyskinesia in Parkinson's disease. Parkinsonism Relat Disord. 2001;8(2):101-108.

7. Fahn S, Oakes D, Shoulson I, et al; for the Parkinson Study Group. Levodopa and the progression of Parkinson's disease. $N$ Engl J Med. 2004;351(24):2498-2508.

8. Fahn S. The spectrum of levodopa-induced dyskinesias. Ann Neurol. 2000;47(Suppl 1):2-11.

9. Golbe LI. Young-onset Parkinson's disease: a clinical review. Neurology. 1991;41(2 Pt 1):168-173.

10. Forno LS. Neuropathology of Parkinson's disease. J Neuropathol Exp Neurol. 1996;55(3):259-272.

11. Jellinger KA. Post mortem studies in Parkinson's disease - is it possible to detect brain areas for specific symptoms? J Neural Transm Suppl. 1999;56:1-29.

12. Grace AA, Bunney BS. The control of firing pattern in nigral dopamine neurons: single spike firing. J Neurosci. 1984;4(11):2866-2876.

13. Grace AA. Phasic versus tonic dopamine release and the modulation of dopamine system responsivity: a hypothesis for the etiology of schizophrenia. Neuroscience. 1991;41(1):1-24.

14. Abercrombie ED, Bonatz AE, Zigmond MJ. Effects of L-dopa on extracellular dopamine in striatum of normal and 6-hydroxydopaminetreated rats. Brain Res. 1990;525(1):36-44.

15. Schultz W. Predictive reward signal of dopamine neurons. J Neurophysiol. 1998;80(1):1-27.

16. Venton BJ, Zhang H, Garris PA, Phillips PE, Sulzer D, Wightman RM. Realtime decoding of dopamine concentration changes in the caudate-putamen during tonic and phasic firing. J Neurochem. 2003;87(5): 1284-1295.

17. Olanow CW, Obeso JA, Stocchi F. Continuous dopamine-receptor treatment of Parkinson's disease: scientific rationale and clinical implications. Lancet Neurol. 2006;5(8):677-687.

18. Lewitt PA. Levodopa for the treatment of Parkinson's disease. $N$ Engl J Med. 2008;359(23):2468-2476.

19. Nutt JG, Woodward WR, Beckner RM, et al. Effect of peripheral catechol-O-methyltransferase inhibition on the pharmacokinetics and pharmacodynamics of levodopa in parkinsonian patients. Neurology. 1994;44(5):913-919.

20. Nutt JG. Effect of COMT inhibition on the pharmacokinetics and pharmacodynamics of levodopa in parkinsonian patients. Neurology. 2000;55:(11 Supp1 4):S33-S37.

21. De la Fuente-Fernández R, Sossi V, Huang Z, et al. Levodopa-induced changes in synaptic dopamine levels increase with progression of Parkinson's disease: implications for dyskinesias. Brain. 2004;127 (Pt 12):2747-2754.

22. Olanow CW, Obeso JA. Preventing levodopa-induced dyskinesias. Ann Neurol. 2000;47(4 Suppl 1):S167-S176.

23. Nutt JG, Carter JH, Lea ES, Woodward WR. Motor fluctuations during continuous levodopa infusions in patients with Parkinson's disease. Mov Disord. 1997;12(3):285-292.

24. Stocchi F, Vacca L, Ruggieri S, Olanow CW. Intermittent vs continuous levodopa administration in patients with advanced Parkinson disease: a clinical and pharmacokinetic study. Arch Neurol. 2005;62(6): 905-910.

25. Antonini A, Isaias IU, Canesi M, et al. Duodenal levodopa infusion for advanced Parkinson's disease: 12-month treatment outcome. Mov Disord. 2007;22(8):1145-1149.

26. Pearce RK, Banerji T, Jenner P, Marsden CD. De novo administration of ropinirole and bromocriptine induces less dyskinesia than L-dopa in the MPTP-treated marmoset. Mov Disord. 1998;13(2):234-241.

27. Rascol O, Brooks DJ, Korczyn AD, de Deyn PP, Clarke CE, Lang AE; for the 056 Study Group. A five-year study of the incidence of dyskinesia in patients with early Parkinson's disease who were treated with ropinirole or levodopa. N Engl J Med. 2000;342(20):1484-1491. 
28. Olanow CW. The scientific basis for the current treatment of Parkinson's disease. Annu Rev Med. 2004;55:41-60.

29. Stocchi F, Rascol O, Kieburtz K, et al. Initiating levodopa/carbidopa therapy with and without entacapone in early Parkinson disease: the STRIDE-PD study. Ann Neurol. 2010;68(1):18-27.

30. Smith LA, Jackson MJ, Al-Barghouthy G, et al. Multiple small doses of levodopa plus entacapone produce continuous dopaminergic stimulation and reduce dyskinesia induction in MPTP-treated drug-naive primates. Mov Disord. 2005;20(3):306-314.

31. Suzuki K, Nakazato H, Matsui H, et al. Genetic polymorphisms of estrogen receptor alpha, CYP19, catechol-O-methyltransferase are associated with familial prostate carcinoma risk in a Japanese population. Cancer. 2003;98(7):1411-1416.

32. Tanaka Y, Sasaki M, Shiina H, et al. Catechol-O-methyltransferase gene polymorphisms in benign prostatic hyperplasia and sporadic prostate cancer. Cancer Epidemiol Biomarkers Prev. 2006;15(2):238-244.

33. Shoulson I, Glaubiger GA, Chase TN. On-off response. Clinical and biochemical correlations during oral and intravenous levodopa administration in parkinsonian patients. Neurology. 1975;25(12): 1144-1148.

34. Hardie RJ, Lees AJ, Stern GM. On-off fluctuations in Parkinson's disease. A clinical and neuropharmacological study. Brain. 1984;107 (Pt 2):487-506.

35. Bredberg E, Nilsson D, Johansson K, et al. Intraduodenal infusion of a water-based levodopa dispersion for optimisation of the therapeutic effect in severe Parkinson's disease. Eur J Clin Pharmacol. 1993;45(2): $117-122$.

36. Sage JI, Schuh L, Heikkila RE, Duvoisin RC. Continuous duodenal infusions of levodopa: plasma concentrations and motor fluctuations in Parkinson's disease. Clin Neuropharmacol. 1988;11(1):36-44.

37. Nyholm D, Nilsson Remahl AI, Dizdar N, et al. Duodenal levodopa infusion monotherapy vs oral polypharmacy in advanced Parkinson disease. Neurology. 2005;64(2):216-223.

38. Nilsson D, Nyholm D, Aquilonius SM. Duodenal levodopa infusion in Parkinson's disease - long-term experience. Acta Neurol Scand. 2001;104(6):343-348.

39. Devos D; for the French DUODOPA Study Group. Patient profile, indications, efficacy and safety of duodenal levodopa infusion in advanced Parkinson's disease. Mov Disord. 2009;24(7) :993-1000.

40. Nyholm D. Pharmacokinetics of levodopa/carbidopa infusion with and without oral catechol-O-methyl transferase (COMT) inhibitors (DuoCOMT). Available from: http://clinicaltrials.gov/ct2/show/ NCT00906828. Accessed December 2010.

41. Pekkonen E. Duodenal levodopa infusion, quality of life and autonomic nervous system in Parkinson's disease. Available from: http:// clinicaltrials.gov/ct2/show/NCT00914134. Accessed December 2010.

42. Lundqvist C, Beiske A. Continuous delivery of levodopa in patients with advanced idiopathic Parkinsons disease - cost-benefit. Available from: http://clinicaltrials.gov/ct2/show/NCT00272688. Accessed December 2010.

43. Nyholm D. Different dyskinesias in Parkinson's disease and their relation to levodopa pharmacokinetics (DYSK-PD-2007). Available from: http:/clinicaltrials.gov/ct2/show/NCT00888186. Accessed December 2010.

44. Kurlan R, Rothfield KP, Woodward WR, et al. Erratic gastric emptying of levodopa may cause "random" fluctuations of parkinsonian mobility. Neurology. 1988;38(3):419-421.

45. Djaldetti R, Baron J, Ziv I, Melamed E. Gastric emptying in Parkinson's disease: patients with and without response fluctuations. Neurology. 1996;46(4):1051-1054.

46. Pfeiffer RF. Gastrointestinal dysfunction in Parkinson's disease. Lancet Neurol. 2003;2(2):107-116.

47. Goetze O, Nikodem AB, Wiezcorek J, et al. Predictors of gastric emptying in Parkinson's disease. Neurogastroenterol Motil. 2006;18(5): 369-375.
48. Steiger MJ, Stocchi F, Carta A, et al. The clinical efficacy of oral levodopa methyl ester solution in reversing afternoon "off" periods in Parkinson's disease. Clin Neuropharmacol. 1991;14(3):241-244.

49. Stocchi F, Fabbri L, Vecsei L, Krygowska-Wajs A, Monici Preti PA, Ruggieri SA. Clinical efficacy of a single afternoon dose of effervescent levodopa-carbidopa preparation (CHF 1512) in fluctuating Parkinson disease. Clin Neuropharmacol. 2007;30(1):18-24.

50. Stocchi F, Zappia M, Dall'Armi V, Kulisevsky J, Lamberti P, Obeso JA; for the Melevodopa Plus Carbidopa Study Group. Melevodopa/carbidopa effervescent formulation in the treatment of motor fluctuations in advanced Parkinson's disease. Mov Disord. 2010; 25(12):1881-1887.

51. Chen D. An exploratory study of XP21279 (with Lodosyn ${ }^{\circledR}$ ) and Sinemet ${ }^{\circledR}$ in Parkinson's disease subjects. Available from: http:// clinicaltrials.gov/ct2/show/NCT00914602. Accessed December 2010.

52. XenoPort. Product candidates, XP21279. Available from: http://www. xenoport.com/product/xp21279.htm. Accessed December 2010.

53. Hsu A, Verhagen Metman L, Ellenbogen A, et al. Comparison of IPX066, a novel extended-release oral carbidopa-levodopa formulation, to immediate-release carbidopa-levodopa in patients with advanced Parkinson's disease. Am Acad Neurol. 2010;74(Suppl 2):A350.

54. Impax Study Director. A study to evaluate the safety and efficacy of IPX066 in subjects with Parkinson's disease (APEX-PD). Available from: http://clinicaltrials.gov/ct2/show/NCT00880620. Accessed December 2010.

55. Ferré S, O'Connor WT, Fuxe K, Ungerstedt U. The striopallidal neuron: a main locus for adenosine-dopamine interactions in the brain. J Neurosci. 1993;13(12):5402-5406.

56. Svenningsson P, Le Moine C, Aubert I, Burbaud P, Fredholm BB, Bloch B. Cellular distribution of adenosine A2A receptor mRNA in the primate striatum. J Comp Neurol. 1998;399(2):229-240.

57. Ferré S, Fredholm BB, Morelli M, Popoli P, Fuxe K. Adenosinedopamine receptor-receptor interactions as an integrative mechanism in the basal ganglia. Trends Neurosci. 1997;20(10):482-487.

58. Mori A, Shindou T. Modulation of GABAergic transmission in the striatopallidal system by adenosine $\mathrm{A} 2 \mathrm{~A}$ receptors: a potential mechanism for the antiparkinsonian effects of A2A antagonists. Neurology. 2003;61(11 Suppl 6):S44-S48.

59. Fenu S, Pinna A, Ongini E, Morelli M. Adenosine A2A receptor antagonism potentiates L-DOPA-induced turning behaviour and c-fos expression in 6-hydroxydopamine-lesioned rats. Eur J Pharmacol. 1997;321(2):143-147.

60. Rose S, Ramsay Croft N, Jenner P. The novel adenosine A2a antagonist ST1535 potentiates the effects of a threshold dose of 1-dopa in unilaterally 6-OHDA-lesioned rats. Brain Res. 2007;1133(1):110-114.

61. Kanda T, Jackson MJ, Smith LA, et al. Adenosine A2A antagonist: a novel antiparkinsonian agent that does not provoke dyskinesia in parkinsonian monkeys. Ann Neurol. 1998;43(4):507-513.

62. Lundblad M, Vaudano E, Cenci MA. Cellular and behavioural effects of the adenosine $\mathrm{A} 2 \mathrm{~A}$ receptor antagonist $\mathrm{KW}-6002$ in a rat model of L-DOPA-induced dyskinesia. J Neurochem. 2003;84(6):1398-1410.

63. Kanda T, Jackson MJ, Smith LA, et al. Combined use of the adenosine A(2A) antagonist KW-6002 with L-DOPA or with selective D1 or D2 dopamine agonists increases antiparkinsonian activity but not dyskinesia in MPTP-treated monkeys. Exp Neurol. 2000;162(2):321-327.

64. Bara-Jimenez W, Sherzai A, Dimitrova T, et al. Adenosine A(2A) receptor antagonist treatment of Parkinson's disease. Neurology. 2003; 61(3):293-296.

65. Hauser RA, Hubble JP, Truong DD; for the Istradefylline US-001 Study Group. Randomized trial of the adenosine $\mathrm{A}(2 \mathrm{~A})$ receptor antagonist istradefylline in advanced PD. Neurology. 2003;61(3):297-303.

66. Lewitt PA, Guttman M, Tetrud JW, et al; for the 6002-US-005 Study Group. Adenosine A2A receptor antagonist istradefylline (KW-6002) reduces "off" time in Parkinson's disease: a double-blind, randomized, multicenter clinical trial (6002-US-005). Ann Neurol. 2008;63(3):295-302. 
67. Stacy M, Silver D, Mendis T, et al. A 12-week, placebo-controlled study (6002-US-006) of istradefylline in Parkinson disease. Neurology. 2008; 70(23):2233-2240.

68. Hauser RA, Shulman LM, Trugman JM, et al; for the Istradefylline 6002-US-013 Study Group. Study of istradefylline in patients with Parkinson's disease on levodopa with motor fluctuations. Mov Disord. 2008;23(15):2177-2185.

69. Guttman M. Efficacy of istradefylline in Parkinson's disease patients treated with levodopa with motor response complications: primary efficacy results of the KW-6002 US-018 study. Mov Disord. 2006;21(Suppl 15):S585.

70. ClinicalTrials.gov. KW-6002 to treat Parkinson's disease. NCT00006337. Available from: http://clinicaltrials.gov/ct2/show/NCT00006337. Accessed December 2010.

71. Vernalis. 2nd generation A2A antagonist. Available from: http:// www.vernalis.com/development/cns/2nd-generation-a2a-antagonist\#. Accessed December 2010.

72. ClinicalTrials.gov. A phase 2, 12-week, double-blind, dose-finding, placebo-controlled study to assess the efficacy and safety of a range of SCH 420814 doses in subjects with moderate to severe Parkinson's disease experiencing motor fluctuations and dyskinesias. Available from: http:// clinicaltrials.gov/ct2/show/NCT00406029. Accessed December 2010.

73. Hauser RA, Pourcher E, Micheli F, et al. Efficacy of preladenant, a novel A2A antagonist, as an adjunct to levodopa for the treatment of Parkinson's disease. Presented at Movement Disorder Society's 13th International Congress of Parkinson's Disease and Movements Disorders, Paris, France (7-11 Jun 2009). Abstract Tu-185.

74. Huyck SB, Wolski K, Cantillon M. Impact of A2A receptor antagonist preladenant on dyskinesia in moderate to severe Parkinson's disease: post hoc analysis of dose-finding study. Presented at Movement Disorder Society's 13th International Congress of Parkinson's Disease and Movements Disorders, Paris, France (7-11 Jun 2009). Abstract Tu-187.

75. Schering-Plough Research Institute. A placebo- and active-controlled study of preladenant in early Parkinson's disease (study P05664 AM2). Available from: http://clinicaltrials.gov/ct2/show/NCT01155479. Accessed December 2010.

76. Schering-Plough Research Institute. A placebo- and active controlled study of preladenant in subjects with moderate to severe Parkinson"s disease (study P04938 AM2). Available from: http://clinicaltrials.gov/ ct2/show/NCT01155466. Accessed December 2010.

77. Synosia Therapeutics. Pipeline. Available from: http://www.synosia com/pipeline.aspx. Accessed December 2010

78. Sigma-Tau. Research development stages. Available from: http://www. sigma-tau.it/eng/fasidisviluppo.asp. Accessed December 2010.

79. Ross GW, Abbott RD, Petrovitch H, et al. Association of coffee and caffeine intake with the risk of Parkinson disease. JAMA. 2000;283(20): 2674-2679.

80. Ascherio A, Zhang SM, Hernán MA, et al. Prospective study of caffeine consumption and risk of Parkinson's disease in men and women. Ann Neurol. 2001;50(1):56-63.

81. Tan EK, Tan C, Fook-Chong SM, et al. Dose-dependent protective effect of coffee, tea, and smoking in Parkinson's disease: a study in ethnic Chinese. J Neurol Sci. 2003;216(1):163-167.

82. Hu G, Bidel S, Jousilahti P, Antikainen R, Tuomilehto J. Coffee and tea consumption and the risk of Parkinson's disease. Mov Disord. 2007;22(15):2242-2248.

83. Chen JF, Xu K, Petzer JP, et al. Neuroprotection by caffeine and A(2A) adenosine receptor inactivation in a model of Parkinson's disease. J Neurosci. 2001;21(10):RC143.

84. Ikeda K, Kurokawa M, Aoyama S, Kuwana Y. Neuroprotection by adenosine A2A receptor blockade in experimental models of Parkinson's disease. J Neurochem. 2002;80(2):262-270.

85. Pierri M, Vaudano E, Sager T, Englund U. KW-6002 protects from MPTP induced dopaminergic toxicity in the mouse. Neuropharmacology. 2005;48(4):517-524.
86. Jenner P, Mori A, Hauser RA, Morelli M, Fredholm BB, Chen JF. Adenosine, adenosine A2A antagonists, and Parkinson's disease. Parkinsonism Relat Disord. 2009;15(6):406-413.

87. Blandini F, Armentero MT, Fancellu R, Blaugrund E, Nappi G. Neuroprotective effect of rasagiline in a rodent model of Parkinson's disease. Exp Neurol. 2004;187(2):455-459.

88. Kupsch A, Sautter J, Götz ME, et al. Monoamine oxidase-inhibition and MPTP-induced neurotoxicity in the non-human primate: comparison of rasagiline (TVP 1012) with selegiline. J Neural Transm. 2001;108(8-9):985-1009.

89. Parkinson Study Group. A controlled, randomized, delayed-start study of rasagiline in early Parkinson disease. Arch Neurol. 2004; 61(4):561-566.

90. Olanow CW, Rascol O, Hauser RA, et al; for the ADAGIO Study Investigators. A double-blind, delayed-start trial of rasagiline in Parkinson's disease. N Engl J Med. 2009;361(13): 1268-1278

91. Kieburtz K. ADAGIO misses a beat? Lancet Neurol. 2009;8(12): 1081-1082.

92. Ahlskog JE, Uitti RJ. Rasagiline, Parkinson neuroprotection, and delayed-start trials: still no satisfaction? Neurology. 2010;74(14): 1143-1148.

93. Marzo A, Dal Bo L, Monti NC, et al. Pharmacokinetics and pharmacodynamics of safinamide, a neuroprotectant with antiparkinsonian and anticonvulsant activity. Pharmacol Res. 2004; 50(1):77-85.

94. Caccia C, Maj R, Calabresi M, et al. Safinamide: from molecular targets to a new anti-Parkinson drug. Neurology. 2006;67 (7 Suppl 2):S18-S23.

95. Stocchi F, Arnold G, Onofrj M, et al; for the Safinamide Parkinson's Study Group. Improvement of motor function in early Parkinson disease by safinamide. Neurology. 2004;63(4):746-748.

96. Borgohain R, Szasz J, Bhatt M. Efficacy and safety of safinamide in patients with Parkinson's disease experiencing motor fluctuations: results of a 6-month phase III, randomized, double-blind, placebo-controlled study. 2009. Available from: http://www. movementdisorders.org/congress/congress09/late_breaking abstracts.pdf. Accessed December 2010.

97. Willmer J. Safinamide in levodopa induced dyskinesia in Parkinson's disease subjects (safinamide-LID). Available from: http://clinicaltrials. gov/ct2/show/NCT01113320. Accessed December 2010.

98. Schapira AH. Safinamide in the treatment of Parkinson's disease. Expert Opin Pharmacother. 2010;11(13):2261-2268.

99. Stacy M, Galbreath A. Optimizing long-term therapy for Parkinson disease: levodopa, dopamine agonists, and treatment-associated dyskinesia. Clin Neuropharmacol. 2008;31(1):51-56.

100. Hauser RA, Rascol O, Korczyn AD, et al. Ten-year follow-up of Parkinson's disease patients randomized to initial therapy with ropinirole or levodopa. Mov Disord. 2007;22(16): 2409-2417.

101. Holloway R, Marek K, Biglan K, et al; for the Parkinson Study Group CALM Cohort Investigators. Long-term effect of initiating pramipexole vs levodopa in early Parkinson disease. Arch Neurol. 2009;66(5):563-570.

102. Parkinson Study Group. Dopamine transporter brain imaging to assess the effects of pramipexole vs levodopa on Parkinson disease progression. JAMA. 2002;287(13):1653-1661.

103. Whone AL, Watts RL, Stoessl AJ, et al; for the REAL-PET Study Group. Slower progression of Parkinson's disease with ropinirole versus levodopa: the REAL-PET study. Ann Neurol. 2003;54(1):93-101.

104. Schapira AH, Albrecht S, Barone P, et al. Immediate vs delayedstart pramipexole in early Parkinson's disease: the PROUD study. Parkinsonism Relat Disord. 2009;15(Suppl 2):S81.

105. Schapira AH, Albrecht S, Barone P, et al. Rationale for delayed-start study of pramipexole in Parkinson's disease: the PROUD study. Mov Disord. 2010;25(11):1627-1632. 
106. Stocchi F, Hersh BP, Scott BL, Nausieda PA, Giorgi L; for the Ease-PD Monotherapy Study Investigators. Ropinirole 24-hour prolonged release and ropinirole immediate release in early Parkinson's disease: a randomized, double-blind, non-inferiority crossover study. Curr Med Res Opin. 2008;24(10):2883-2895.

107. Pahwa R, Stacy MA, Factor SA, et al; for the EASE-PD Adjunct Study Investigators. Ropinirole 24-hour prolonged release: randomized, controlled study in advanced Parkinson disease. Neurology. 2007; 68(14):1108-1115.

108. Hersh BP, Earl NL, Hauser RA, Stacy M. Early treatment benefits of ropinirole prolonged release in Parkinson's disease patients with motor fluctuations. Mov Disord. 2010;25(7):927-931.

109. Hauser RA, Schapira AH, Rascol O, et al. Randomized, doubleblind, multicenter evaluation of pramipexole extended release once daily in early Parkinson's disease. Mov Disord. 2010;25(15): 2542-2549.

110. Driver-Dunckley E, Samanta J, Stacy M. Pathological gambling associated with dopamine agonist therapy in Parkinson's disease. Neurology. 2003;61(3):422-423.

111. Weintraub D, Siderowf AD, Potenza MN, et al. Association of dopamine agonist use with impulse control disorders in Parkinson disease. Arch Neurol. 2006;63(7):969-973.

112. Voon V, Hassan K, Zurowski M, et al. Prevalence of repetitive and reward-seeking behaviors in Parkinson disease. Neurology. 2006; 67(7):1254-1257.

113. Evans AH, Strafella AP, Weintraub D, Stacy M. Impulsive and compulsive behaviors in Parkinson's disease. Mov Disord. 2009; 24(11):1561-1570

114. Weintraub D, Koester J, Potenza MN, et al. Impulse control disorders in Parkinson disease: a cross-sectional study of 3090 patients. Arch Neurol. 2010;67(5):589-595.

115. Thomas A, Bonanni L, Gambi F, di Iorio A, Onofrj M. Pathological gambling in Parkinson disease is reduced by amantadine. Ann Neurol. 2010;68(3):400-404.

116. Weintraub D, Sohr M, Potenza MN, et al. Amantadine use associated with impulse control disorders in Parkinson disease in cross-sectional study. Ann Neurol. 2010;68(6):963-968.

117. Weintraub D. Naltrexone for impulse control disorders in Parkinson's disease. Available from: http://clinicaltrials.gov/ct2/show/ NCT01052831. Accessed December 2010.

118. Modi G, Pillay V, Choonara YE. Advances in the treatment of neurodegenerative disorders employing nanotechnology. Ann N Y Acad Sci. 2010;1184:154-172.

119. Modi G, Pillay V, Choonara YE, Ndesendo VM, du Toit LC, Naidoo D. Nanotechnological applications for the treatment of neurodegenerative disorders. Prog Neurobiol. 2009;88(4):272-285.

120. Staples M. Microchips and controlled-release drug reservoirs. Wiley Interdiscip Rev Nanomed Nanobiotechnol. 2010;2(4):400-417.

121. Linazasoro G; for the Nanotechnologies for Neurodegenerative Diseases Study Group of the Basque Country (NANEDIS). Potential applications of nanotechnologies to Parkinson's disease therapy. Parkinsonism Relat Disord. 2008;14(5):383-392.

122. Bergman H, Wichmann T, DeLong MR. Reversal of experimental parkinsonism by lesions of the subthalamic nucleus. Science. 1990; 249(4975):1436-1438.

123. Aziz TZ, Peggs D, Sambrook MA, Crossman AR. Lesion of the subthalamic nucleus for the alleviation of 1-methyl-4-phenyl-1,2,3, 6-tetrahydropyridine (MPTP)-induced parkinsonism in the primate. Mov Disord. 1991;6(4):288-292.

124. Benazzouz A, Gross C, Féger J, Boraud T, Bioulac B. Reversal of rigidity and improvement in motor performance by subthalamic highfrequency stimulation in MPTP-treated monkeys. Eur J Neurosci. 1993;5(4):382-389.

125. Wichmann T, Bergman H, DeLong MR. The primate subthalamic nucleus. III. Changes in motor behavior and neuronal activity in the internal pallidum induced by subthalamic inactivation in the MPTP model of parkinsonism. J Neurophysiol. 1994;72(2):521-530.
126. Kleiner-Fisman G, Fisman DN, Sime E, Saint-Cyr JA, Lozano AM, Lang AE. Long-term follow up of bilateral deep brain stimulation of the subthalamic nucleus in patients with advanced Parkinson disease. J Neurosurg. 2003;99(3):489-495.

127. Weaver FM, Follett K, Stern M, et al; for the CSP 468 Study Group. Bilateral deep brain stimulation vs best medical therapy for patients with advanced Parkinson disease: a randomized controlled trial. JAMA. 2009;301(1):63-73.

128. Follett KA, Weaver FM, Stern M, et al; for the CSP 468 Study Group. Pallidal versus subthalamic deep-brain stimulation for Parkinson's disease. N Engl J Med. 2010;362(22):2077-2091.

129. Mazzone P, Lozano A, Stanzione P, et al. Implantation of human pedunculopontine nucleus: a safe and clinically relevant target in Parkinson's disease. Neuroreport. 2005;16(17):1877-1881.

130. Plaha P, Gill SS. Bilateral deep brain stimulation of the pedunculopontine nucleus for Parkinson's disease. Neuroreport. 2005;16(17): $1883-1887$.

131. Moro E, Hamani C, Poon YY, et al. Unilateral pedunculopontine stimulation improves falls in Parkinson's disease. Brain. 2010;133 (Pt 1):215-224.

132. Ferraye MU, Debû B, Fraix V, et al. Effects of pedunculopontine nucleus area stimulation on gait disorders in Parkinson's disease. Brain. 2010;133(Pt 1):205-214.

133. Benabid AL, Chabardes S, Mitrofanis J, Pollak P. Deep brain stimulation of the subthalamic nucleus for the treatment of Parkinson's disease. Lancet Neurol. 2009;8(1):67-81.

134. Benabid AL, Pollak P, Gao D, et al. Chronic electrical stimulation of the ventralis intermedius nucleus of the thalamus as a treatment of movement disorders. J Neurosurg. 1996;84(2): 203-214.

135. Meissner W, Leblois A, Hansel D, et al. Subthalamic high frequency stimulation resets subthalamic firing and reduces abnormal oscillations. Brain. 2005;128(Pt 10):2372-2382.

136. Welter ML, Houeto JL, Bonnet AM, et al. Effects of high-frequency stimulation on subthalamic neuronal activity in parkinsonian patients. Arch Neurol. 2004;61(1):89-96.

137. Xia R, Berger F, Piallat B, Benabid AL. Alteration of hormone and neurotransmitter production in cultured cells by high and low frequency electrical stimulation. Acta Neurochir (Wien). 2007;149(1): 67-73.

138. Harnack D, Meissner W, Jira JA, Winter C, Morgenstern R, Kupsch A. Placebo-controlled chronic high-frequency stimulation of the subthalamic nucleus preserves dopaminergic nigral neurons in a rat model of progressive Parkinsonism. Exp Neurol. 2008;210(1): 257-260.

139. Maesawa S, Kaneoke Y, Kajita Y, et al. Long-term stimulation of the subthalamic nucleus in hemiparkinsonian rats: neuroprotection of dopaminergic neurons. J Neurosurg. 2004;100(4): 679-687.

140. Temel Y, Visser-Vandewalle V, Kaplan S, et al. Protection of nigral cell death by bilateral subthalamic nucleus stimulation. Brain Res. 2006;1120(1):100-105.

141. Wallace BA, Ashkan K, Heise CE, et al. Survival of midbrain dopaminergic cells after lesion or deep brain stimulation of the subthalamic nucleus in MPTP-treated monkeys. Brain. 2007;130 (Pt 8):2129-2145.

142. Spieles-Engemann AL, Behbehani MM, Collier TJ, et al. Stimulation of the rat subthalamic nucleus is neuroprotective following significant nigral dopamine neuron loss. Neurobiol Dis. 2010;39(1): 105-115.

143. Bergman H, Wichmann T, Karmon B, DeLong MR. The primate subthalamic nucleus. II. Neuronal activity in the MPTP model of parkinsonism. J Neurophysiol. 1994;72(2):507-520.

144. Crossman AR, Mitchell IJ, Sambrook MA. Regional brain uptake of 2-deoxyglucose in N-methyl-4-phenyl-1,2,3,6-tetrahydropyridine (MPTP)-induced parkinsonism in the macaque monkey. Neuropharmacology. 1985;24(6):587-591. 
145. Eidelberg D, Moeller JR, Dhawan V, et al. The metabolic topography of parkinsonism. J Cereb Blood Flow Metab. 1994;14(5): 783-801.

146. Deep-Brain Stimulation for Parkinson's Disease Study Group. Deep-brain stimulation of the subthalamic nucleus or the pars interna of the globus pallidus in Parkinson's disease. $N$ Engl J Med. 2001;345(13):956-963.

147. Charles PD, van Blercom N, Krack P, et al. Predictors of effective bilateral subthalamic nucleus stimulation for PD. Neurology. 2002; 59(6):932-934.

148. Deuschl G, Schade-Brittinger C, Krack P, et al; for the German Parkinson Study Group, Neurostimulation Section. A randomized trial of deep-brain stimulation for Parkinson's disease. $N$ Engl J Med. 2006;355(9):896-908.

149. Volkmann J. Deep brain stimulation for the treatment of Parkinson's disease. J Clin Neurophysiol. 2004;21(1):6-17.

150. Morgante L, Morgante F, Moro E, et al. How many parkinsonian patients are suitable candidates for deep brain stimulation of subthalamic nucleus? Results of a questionnaire. Parkinsonism Relat Disord. 2007;13(8):528-531.

151. Espay AJ, Vaughan JE, Marras C, Fowler R, Eckman MH. Early versus delayed bilateral subthalamic deep brain stimulation for parkinson's disease: a decision analysis. Mov Disord. 2010;25(10): 1456-1463.

152. Deuschl G; for the German Parkinson Study Group (GPS). Controlled trial of deep brain stimulation in early patients with Parkinson's disease. Available from: http://clinicaltrials.gov/ct2/show/NCT00354133. Accessed December 2010.

153. Charles PD. Deep brain stimulation (DBS) for early stage Parkinson's disease (PD). Available from: http://clinicaltrials.gov/ct2/show/ NCT00282152. Accessed December 2010.

154. Keeler CE. Gene therapy. J Hered. 1947;38(10):294-298.

155. Morrow JF. The prospects for gene therapy in humans. Ann NYAcad Sci. 1976;265:13-21.

156. Nagatsu T, Sawada M. Biochemistry of postmortem brains in Parkinson's disease: historical overview and future prospects. J Neural Transm Suppl. 2007;(72):113-120.

157. Bankiewicz KS, Forsayeth J, Eberling JL, et al. Long-term clinical improvement in MPTP-lesioned primates after gene therapy with AAV-hAADC. Mol Ther. 2006;14(4):564-570.

158. Shen Y, Muramatsu S, Ikeguchi K, et al. Triple transduction with adeno-associated virus vectors expressing tyrosine hydroxylase, aromatic-L-amino-acid decarboxylase, and GTP cyclohydrolase I for gene therapy of Parkinson's disease. Hum Gene Ther. 2000;11(11): 1509-1519.

159. Muramatsu S, Fujimoto K, Ikeguchi K, et al. Behavioral recovery in a primate model of Parkinson's disease by triple transduction of striatal cells with adeno-associated viral vectors expressing dopaminesynthesizing enzymes. Hum Gene Ther. 2002;13(3):345-354.

160. Jarraya B, Boulet S, Ralph GS, et al. Dopamine gene therapy for Parkinson's disease in a nonhuman primate without associated dyskinesia. Sci Transl Med. 2009;1(2):2ra4.

161. Oxford BioMedica. Oxford BioMedica announces two-year phase I/II results of ProSavin ${ }^{\circledR}$ in Parkinson's disease - 6/14/2010 Available from: http://www.oxfordbiomedica.co.uk/page.asp? pageid=59\&newsid=259. Accessed December 2010 .

162. Palfi S. Phase I/II study of the safety, efficacy and dose evaluation of ProSavin for the treatment of bilateral idiopathic Parkinson's disease. Available from: http://clinicaltrials.gov/ct2/show/NCT00627588. Accessed December 2010.

163. Bankiewicz KS, Eberling JL, Kohutnicka M, et al. Convectionenhanced delivery of AAV vector in parkinsonian monkeys; in vivo detection of gene expression and restoration of dopaminergic function using pro-drug approach. Exp Neurol. 2000;164(1):2-14.

164. Eberling JL, Jagust WJ, Christine CW, et al. Results from a phase I safety trial of hAADC gene therapy for Parkinson disease. Neurology. 2008;70(21):1980-1983.
165. Muramatsu S, Fujimoto K, Kato S, et al. A phase I study of aromatic L-amino acid decarboxylase gene therapy for Parkinson's disease. $\mathrm{Mol}$ Ther. 2010;18(9):1731-1735.

166. Stocchi F, Ruggieri S, Vacca L, Olanow CW. Prospective randomized trial of lisuride infusion versus oral levodopa in patients with Parkinson's disease. Brain. 2002;125(Pt 9):2058-2066.

167. Nutt JG, Obeso JA, Stocchi F. Continuous dopamine-receptor stimulation in advanced Parkinson's disease. Trends Neurosci. 2000; 23(10 Suppl):S109-S115.

168. Chase TN. Levodopa therapy: consequences of the nonphysiologic replacement of dopamine. Neurology. 1998;50(5 Suppl 5):S17-S25.

169. Carlsson T, Winkler C, Burger C, et al. Reversal of dyskinesias in an animal model of Parkinson's disease by continuous L-DOPA delivery using rAAV vectors. Brain. 2005;128(Pt 3):559-569.

170. Kaplitt MG, Feigin A, Tang C, et al. Safety and tolerability of gene therapy with an adeno-associated virus (AAV) borne GAD gene for Parkinson's disease: an open label, phase I trial. Lancet. 2007; 369(9579):2097-2105.

171. Stoessl AJ. Gene therapy for Parkinson's disease: early data. Lancet. 2007;369(9579):2056-2058.

172. Schapira AH, Olanow CW. Neuroprotection in Parkinson disease: mysteries, myths, and misconceptions. JAMA. 2004;291(3): 358-364.

173. Lin LF, Doherty DH, Lile JD, Bektesh S, Collins F. GDNF: a glial cell line-derived neurotrophic factor for midbrain dopaminergic neurons. Science. 1993;260(5111):1130-1132.

174. Nutt JG, Burchiel KJ, Comella CL, et al; for the ICV GDNF Study Group. Randomized, double-blind trial of glial cell line-derived neurotrophic factor (GDNF) in PD. Neurology. 2003;60(1):69-73.

175. Kordower JH, Palfi S, Chen EY, et al. Clinicopathological findings following intraventricular glial-derived neurotrophic factor treatment in a patient with Parkinson's disease. Ann Neurol. 1999;46(3): 419-424.

176. Kirik D, Rosenblad C, Bjorklund A, Mandel RJ. Long-term rAA $\mathrm{V}$-mediated gene transfer of GDNF in the rat Parkinson's model: intrastriatal but not intranigral transduction promotes functional regeneration in the lesioned nigrostriatal system. J Neurosci. 2000; 20(12):4686-4700.

177. Wang L, Muramatsu S, Lu Y, et al. Delayed delivery of AAV-GDNF prevents nigral neurodegeneration and promotes functional recovery in a rat model of Parkinson's disease. Gene Ther. 2002;9(6):381-389.

178. Kordower JH, Emborg ME, Bloch J, et al. Neurodegeneration prevented by lentiviral vector delivery of GDNF in primate models of Parkinson's disease. Science. 2000;290(5492):767-773.

179. Lo Bianco C, Déglon N, Pralong W, Aebischer P. Lentiviral nigral delivery of GDNF does not prevent neurodegeneration in a genetic rat model of Parkinson's disease. Neurobiol Dis. 2004;17(2): 283-289.

180. Gill SS, Patel NK, Hotton GR, et al. Direct brain infusion of glial cell line-derived neurotrophic factor in Parkinson disease. Nat Med. 2003;9(5):589-595.

181. Patel NK, Bunnage M, Plaha P, Svendsen CN, Heywood P, Gill SS. Intraputamenal infusion of glial cell line-derived neurotrophic factor in PD: a two-year outcome study. Ann Neurol. 2005;57(2): 298-302.

182. Lang AE, Gill S, Patel NK, et al. Randomized controlled trial of intraputamenal glial cell line-derived neurotrophic factor infusion in Parkinson disease [Erratum in: Ann Neurol. 2006;60(6):747]. Ann Neurol. 2006;59(3):459-466

183. Gasmi M, Herzog CD, Brandon EP, et al. Striatal delivery of neurturin by CERE-120, an AAV2 vector for the treatment of dopaminergic neuron degeneration in Parkinson's disease. Mol Ther. 2007; 15(1):62-68.

184. Gasmi M, Brandon EP, Herzog CD, et al. AAV2-mediated delivery of human neurturin to the rat nigrostriatal system: long-term efficacy and tolerability of CERE-120 for Parkinson's disease. Neurobiol Dis. 2007;27(1):67-76. 
185. Kordower JH, Herzog CD, Dass B, et al. Delivery of neurturin by AAV2 (CERE-120)-mediated gene transfer provides structural and functional neuroprotection and neurorestoration in MPTP-treated monkeys. Ann Neurol. 2006;60(6):706-715.

186. Marks WJ Jr, Ostrem JL, Verhagen L, et al. Safety and tolerability of intraputaminal delivery of CERE-120 (adeno-associated virus serotype 2-neurturin) to patients with idiopathic Parkinson's disease: an open-label, phase I trial. Lancet Neurol. 2008;7(5): 400-408.
187. Siffert J. Double-blind, multicenter, sham surgery controlled study of CERE-120 in subjects with idiopathic Parkinson's disease. Available from: http://clinicaltrials.gov/ct2/show/NCT00400634. AccessedDecember 2010.

188. Klejbor I, Stachowiak EK, Bharali DJ, et al. ORMOSIL nanoparticles as a non-viral gene delivery vector for modeling polyglutamine induced brain pathology. J Neurosci Methods. 2007;165(2):230-243.

189. Parkinson J. An Essay on the Shaking Palsy. London: Sherwood, Neely and Jones; 1817.

\section{Publish your work in this journal}

Drug Design, Development and Therapy is an international, peerreviewed open-access journal that spans the spectrum of drug design and development through to clinical applications. Clinical outcomes, patient safety, and programs for the development and effective, safe, and sustained use of medicines are a feature of the journal, which has also been accepted for indexing on PubMed Central. The manuscript management system is completely online and includes a very quick and fair peer-review system, which is all easy to use. Visit http://www.dovepress.com/testimonials.php to read real quotes from published authors.

Submit your manuscript here: http://www.dovepress.com/drug-design-development-and-therapy-journal 